\title{
Numerical and Experimental Analysis of Properties and Performance of Solar Stills
}

\author{
Ghaleb Ibrahim ${ }^{1}$ and Husham M. Ahmed ${ }^{2}$ \\ ${ }^{1}$ Associate Professor, 2 Professor \\ ${ }^{1}$ American University in Dubai, School of Engineering, \\ Dubai, United Arab Emirates, 1 gibrahim@aud.edu \\ ${ }^{2}$ AMA International University - Bahrain, College of Engineering, \\ Kingdom of Bahrain, 2hmahmed@amaiu.edu.bh
}

\begin{abstract}
Potable water not only is important for life but also for industrial and agricultural purposes. For many decades, the problem of water shortage has been one of the main challenges facing the world. Solar distillation is regarded by many investigators as one of the important methods to solve water scarcity problems. A solar still is a simple device which can be effectively used to convert saline water into fresh water. The productivity depends on many parameters, which among them are transmittance of the cover, thermal properties of the basin and water, and heat loss through the solar still. In this research, the effect of three design parameters (basin heat transfer coefficient, glass absorptivity and glass transmissivity) on performance of the conventional solar still was theoretically investigated and compared with experimental results. Iteration was necessary to obtain the values of the design parameters that produce good matching between the theoretical and experimental results. The effect of overall heat transfer coefficient $U_{b}$ found to be significantly large especially at low values. It was found that reducing the overall heat transfer coefficient from 30 to $0.0 \mathrm{~W} / \mathrm{m}^{2} \mathrm{~K}$ will increase the production rate by $64.02 \%$ and solar still efficiency will also increase accordingly. It was also found that reducing the absorptivity from 0.1 to 0.01 will increase the solar still efficiency by $23.28 \%$.. The results showed that the solution is highly sensitive and depending on the precision of these parameters. It can be concluded that an accurate prior knowledge of these parameters is essential to obtain reasonable results. The experimental and theoretical hourly production rate are in good agreement at $U_{b}=5.9 \mathrm{~W} / \mathrm{m}^{2} \mathrm{~K}, \alpha_{g}=0.075$ and $\tau_{g}=0.845$ where the maximum discrepancy between them is $23 \%$ at around 14:00.
\end{abstract}

Keywords: Productivity; Solar stills; Water desalination; Wick materials;
(C) Copyright 2021 Authors - This is an Open Access article published under the Creative Commons Attribution License terms (http://creativecommons.org/licenses/by/3.0). Unrestricted use, distribution, and reproduction in any medium are permitted, provided the original work is properly cited.

\section{Introduction}

The available amount of fresh water on earth is very limited, and the demands are significantly increased all over the world due to the rapid population growth and considerable increasing trends of agricultural and industrial requirements. Fresh water reserves are continually decreasing. Industrial wastes and sewage discharges have polluted reserves and underground water. The availability of clean and pure drinking water has become one of the most urgent needs for human community in many countries mainly in the Middle East and North Africa. The majority of areas that have deficiencies in fresh water supply have huge amounts of solar energy freely available [1]-[2]. A solar still is a simple device, which can be effectively used to convert saline water into fresh water. The enhancement of solar stills performance and improving their production capacity of distilled water are the main goals of the investigators in recent years [3].The need for a smallscale solar distillation unit increases continuously, especially in arid regions where sunshine is abundant and fresh water is scarce. These devices are suitable for a single house or a small community for providing good quality of drinking water [4].

In order to have a clear idea about energy efficiency, it is convenient to study heat loss of the solar still. Thermal losses mainly occur through the glass cover 
by radiation and convection heat transfer to the ambient and through the bottom of the basin plate via the insulation by conduction and convection of heat transfer to the ambient. A prior knowledge of the outcome form solar still using theoretical model is of great importance to design and manufacture a solar still that meets the xpectation in terms of functionality and productivity [5].

Ref. [6] reported a comprehensive study of heat transfer, mass transfer, and entropy rate of humid air for a single solar still. They concluded that minimum glass thickness and decreasing thermal losses of the solar still (mainly due to heat loss through the basin plate to the ambient) are the best operating parameters that give maximum solar still productivity. Ref. [7] studied the effect of parameters on the performance of solar stills. They found that productivity is largely affected by climatic, operational, and design parameters. Ref. [8] conducted a comprehensive energy analysis of a passive solar distillation system. Applying a set of typical design and operating parameters using a computer program, the temperatures of basin-liner, saline water body and inner and outer glass cover are estimated. They found that a $100 \%$ increase in insulation thickness of the passive solar still will increase the energy efficiency and daily yield by $5.33 \%$ and $5.52 \%$, respectively. Similar results were reported by Ref. [6]. Ref. [9] compared different mathematical models to describe the simultaneous heat and mass transfer process inside solar stills. The results of these models showed a wide range of discrepancy for the estimation of the daily productivity and thermal efficiency of the solar still. Ref. [10] tabulated the simulation parameters used in their model such as transmitivity, emissivity, absorptivity, specific heat and density for the glass, water and basin plate and used as overall heat transfer coefficient of $14 \mathrm{~W} / \mathrm{m}^{2} \mathrm{~K}$. The basin overall heat transfer coefficient used in various publications varied between 2.8 and $20 \mathrm{~W} / \mathrm{m}^{2} \mathrm{~K}$. Although this parameter is of great importance in solar still, most of these works provided no justification or sufficient information with regard to insulation applied in their systems. Therefore, the physical and thermal properties of the insulation materials are important parameters in terms of the solution of theoretical model and so must be accurately known to guaranty reliable results. The transmittance and absorptance of a glass depend on the type and thickness of the glass in particular the angle that the incidence beam of light makes with the normal to the surface. Ref. [11] provided data for the absorption and transmission of thermal radiation by single and double glazed windows (with index of refraction $n=1.2$ ). Ref. [12] studied the effect of glass thickness on performance of flat plate solar collectors for fruits drying. Their results showed that the change in glass thickness results into variation into collector efficiency. They concluded that the use of $4 \mathrm{~mm}$ glass thick improves the performance of air solar collector by $7.6 \%$ compared to 3,5 , and $6 \mathrm{~mm}$ and the $4 \mathrm{~mm}$ glass thickness gave optimal transmittance and convective losses, and hence is the best glazing thickness.

The theoretical modelling is necessary in engineering field. It enables researchers easily, relatively and without essential expenses to investigate the properties and behaviour of a system in any conceivable situation. A prior knowledge of the outcome form solar still using theoretical model is of great importance to design and manufacture a solar still that meets the expectation in terms of functionality and productivity. The present work is a theoretical study applied to solar stills to address the importance of the above-mentioned transmissivity, absorptivity, reflectance and the basin overall heat transfer coefficient and investigate their effect on the performance of the solar still.

\section{THEORETICAL MODELING OF SOLAR STILL 2.1. Principles of Solar Still}

Solar radiation is partially reflected to the outside and partially absorbed by the glass cover and mostly it is transmitted through the glass cover to the water in the basin. The water in turn absorbs small portion of the received solar radiation and transmit the rest to the basin in conventional solar stills. The solar radiation absorbed by water and the heat gain by the water from the basin will raise the water temperature above that of the glass cover. This allows the evaporated water to condense on the glass cover surface. Inside the solar still the increase in water temperature causes the vapor pressure at the air water interface to increase above that in the bulk of the air. Thus, the water evaporates as a result of the vapor pressure difference and the air humidity in the tank rise and so its dew point. Since the glass cover temperature is lower than the dew point of the humid air, condensation occurs on the glass surface. The evaporated water must be compensated to keep the water level in the tank [13]-[15].

\subsection{Thermal Analysis of the Solar Still}

In this work, the model of Ref. [16] who used a time dependent energy balance on solar stills, which will be modified to fit the current work conditions. The 
theoretical model will be using the measured data of the solar intensity, ambient temperature and wind speed given in Ref. [17]. The solution will be conducted at various absorptivity, transmissivity and basin overall heat transfer coefficient. The operation of solar still is governed by the various heat and mass transfer modes occurring in the system. The major energy transport mechanism in the still is shown in figure 1. Applying the conservation of energy to the conventional solar still components, namely the glass cover, saline water and basin, the following three equations are obtained.

Energy gained by the glass cover (from sun and convective, radiative and evaporative heat transfer from water to glass) is equal to the summation of energy lost by radiative and convective heat transfer between glass and sky, and energy stored by glass.

$$
\begin{aligned}
& I_{\mathrm{t}} A_{g} a_{g}+Q_{c, w g}+Q_{r, w g}+Q_{e, w g} \\
& \quad=m_{g} C p_{g}\left(\frac{d T_{g}}{d t}\right)+Q_{r, g s k y}+Q_{c, g s k y}
\end{aligned}
$$

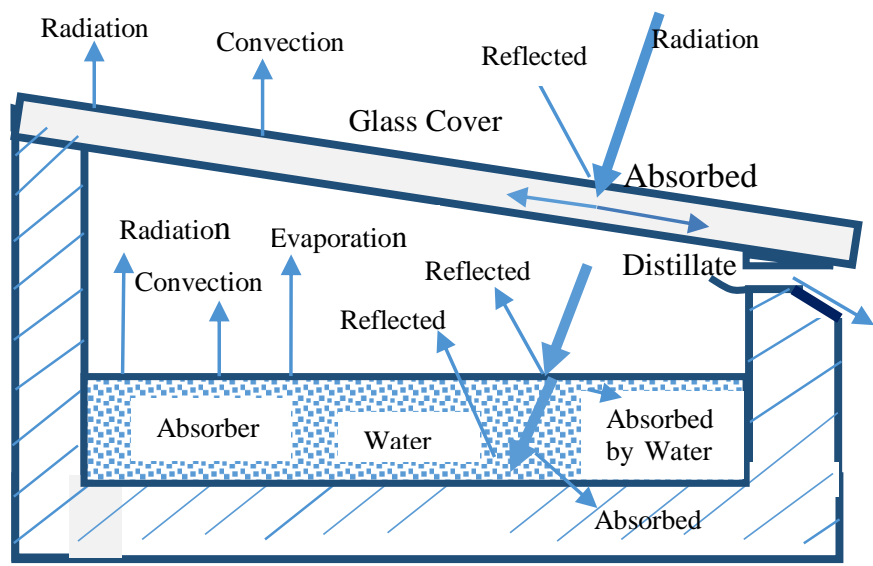

Figure 1 Energy transport mechanism in conventional solar still

Where $I_{\mathrm{t}}$ is radiation intensity, A is surface area, $a$ is the Absorptivity, $\mathrm{Q}$ is rate of heat transfer, $\mathrm{m}$ is mass, $C_{p}$ is specific heat. The subscript $\mathrm{r}$ denotes radiation, $\mathrm{g}$ denotes glass and $\mathrm{T}$ is temperature, $\mathrm{w}$ denotes water, e denotes evaporation and c denotes convection.

Energy received by the saline water in the still (from sun and base) is equal to the summation of energy lost by (1) convective, radiative and evaporative heat transfer between water and glass, plus (2) the energy by the replaced cooler water that replaces the evaporated portion, (3) side wall loss and (4) energy stored by the saline water. The water reflectance is negligibly small.

$$
\begin{aligned}
I_{t} A_{w} a_{w} & +Q_{c, b w}=m_{w} C p_{w}\left(\frac{d T_{w}}{d t}\right)+Q_{c, w g} \\
& +Q_{r, w g}+Q_{e, w g}+Q_{f w}+Q_{s w, l o s s}
\end{aligned}
$$

Where the subscript b denotes basin, fw denotes water feed, sw denotes side wall.

Energy received by the basin (from sun) is equal to the summation of energy (1) lost by convective heat transfer between basin and water, (2) heat lost from the bottom of the basin and (3) energy stored by the basin. It is assumed that all solar radiation reached the basin are absorbed by the basin with zero reflectance

$I_{t} A_{b} a_{b}=m_{b} C p_{b}\left(\frac{d T_{b}}{d t}\right)+Q_{c, b w}+Q_{b, l o s s}$

Where; $a_{g}=\alpha_{g}\left(1-r_{g}\right) ; a_{w}=\alpha_{w} \tau_{g}\left(1-r_{g}\right)$;

$a_{b}=\alpha_{b} \tau_{g} \tau_{w}\left(1-r_{g}\right) \cdot r_{g}$ is the glass reflectance, $\tau_{g}$ is the glass transmittance.

$$
\begin{aligned}
& T_{w}=T_{w}+d T_{w} \\
& T_{g}=T_{g}+d T_{g} \\
& T_{b}=T_{b}+d T_{b} \\
& \frac{d m_{c}}{d t}=\frac{h_{e, w g}\left(T_{w}-T_{g}\right)}{h_{f g}} \\
& Q_{c, b w}=h_{c, b w} A_{b}\left(T_{b}-T_{w}\right) \\
& Q_{b, \text { loss }}=U_{b} A_{b}\left(T_{b}-T_{a}\right) \\
& Q_{f w}=\dot{m}_{e} c_{w}\left(T_{w}-T a\right) \\
& Q_{s w, l o s s}=U_{s w} A_{s w}\left(T_{w}-T_{a}\right)
\end{aligned}
$$

$$
Q_{c, w g}=h_{c, w g} A_{w}\left(T_{w}-T_{g}\right)
$$

Where $m_{c}$ denotes mass of condensate, $h_{f g}$ is the enthalpy of evaporation at $T_{w}, \mathrm{~h}$ is the heat transfer coefficient, $\mathrm{U}$ is the over all heat transfer coefficient.

Heat transfer between water and the glass cover: convective heat transfer coefficient is 


$$
\begin{aligned}
h_{c, w g}=0.884 & \left\{\left(T_{w}-T_{g}\right)\right. \\
& \left.+\frac{\left(P_{w}-P_{g}\right)\left(T_{w}+273.15\right)}{\left(286.9 \times 10^{3}-P_{w}\right)}\right\}^{1 / 3}
\end{aligned}
$$

Where $P_{w}$ is the partial pressure at $T_{w}, P_{g}$ is the partial pressure at $T_{g}$.

The radiative heat transfers is

$$
Q_{r, w g}=h_{r, w g} A_{w}\left(T_{w}-T_{g}\right)
$$

the radiative heat transfer coefficient

$$
\begin{aligned}
& h_{r, w g}=\varepsilon \sigma\left[\left(T_{w}+273.15\right)^{2}+\left(T_{g}+273.15\right)^{2}\right] \\
& \text { Where } \varepsilon=\frac{1}{\left(\frac{1}{\varepsilon_{w}}+\frac{1}{\varepsilon_{g}}-1\right)}
\end{aligned}
$$

The rate of heat transfer due to evaporation is

$$
Q_{e, w g}=h_{e, w g} A_{w}\left(T_{w}-T_{g}\right)
$$

Where the evaporative heat transfer coefficient is

$$
h_{e, w g}=\left(16.273 \times 10^{-3}\right) h_{c, w g} \frac{\left(P_{w}-P_{g}\right)}{\left(T_{w}-T_{g}\right)}
$$

The radiative heat transfers between sky and the glass is

$$
Q_{r, g-s k y}=h_{r, g-s k y} A_{g}\left(T_{g}-T_{s k y}\right)
$$

The radiative heat transfer coefficient is

$h_{r, g-s k y}=\varepsilon \sigma\left[\left(T^{\prime}{ }_{w}\right)^{4}+\left(T^{\prime}{ }^{\prime}\right)^{4}\right]\left(T_{g}+T_{s k y}\right)$

where $T^{\prime}{ }_{w}=T_{w}+273$ and $T_{g}^{\prime}=T_{g}+273$

The effective sky temperature is [16]-[18]

$$
T_{s k y}=T_{a}-6
$$

The convective heat transfers between sky and the glass is

$$
\begin{aligned}
& Q_{c, g-s k y}=h_{c, g-s k y} A_{g}\left(T_{g}-T_{s k y}\right) \\
& h_{c, g-s k y}=2.8+3.0 \mathrm{~V}
\end{aligned}
$$

Where $\mathrm{V}$ is the wind velocity
Solar still efficiency may be calculated using equation 24 .

$\eta=\frac{\sum m_{e} h_{f g}}{\sum I_{t} t}$

Where $\eta$ solar still efficiency.

The daily average percentage of thermal heat loss through the basin to the ambient may be calculated relative to the radiation intensity using equation 25 .

$$
R H L=\frac{\bar{Q}_{b / A_{b}}}{\bar{I}_{t}} 100 \%
$$

Where RHL is the relative heat loss, $\bar{Q}_{b}$ is the daily average rate of heat loss through the basin, $\bar{I}_{t}$ is the daily average radiation intensity

\subsection{Bottom and sidewall heat transfer coefficients;}

Since the solar still contents (basin plate, water and moist air) are at a higher temperatures than the ambient temperatures. A heat loss is expected to occur. Therefore the bottom and side wall are insulated. If the insulation is properly applied, the insulation thermal resistance will be dominant to other thermal resistances. However including all thermal resistance the overall heat transfer coefficient of bottom heat loss is obtained

$U_{b}=(1 / 8)\left(\frac{1}{h_{a}}+\frac{x_{p w}}{k_{p w}}+\frac{x_{i n}}{k_{i n}}+\frac{x_{s}}{k_{s}}\right)$

Where in the thermal resistance of the insulation $\left(\frac{x_{i n}}{k_{i n}}\right)$ is dominant. And the side wall overall heat transfer coefficient is approximated by researcher $[9,19,20]$ as $U_{s w}=U_{b} \frac{A_{s w}}{A b}$

Some researchers embedded the side heat transfer coefficient in the $U_{b}$. In this case a value of $14 \mathrm{~W} / \mathrm{m}^{2} \mathrm{~K}$ [15] and $20 \mathrm{~W} / \mathrm{m}^{2} K$ [7] were used. Ref. [21] took the side wall heat transfer coefficient as $0.5 \mathrm{~W} / \mathrm{m}^{2} \mathrm{~K}$. In this current work the side wall heat loss is obtained as

$U_{s w}=1 /\left(\frac{1}{h_{a}}+\frac{x_{p w}}{k_{p w}}+\frac{x_{i n}}{k_{i n}}+\frac{x_{s}}{k_{s}}+\frac{1}{h_{c w}+h_{r w}}\right)$

Where $h_{c w}=h_{c, w g}$ and $h_{r w}=h_{r, w g}$. These coefficients are time dependent. $x$ thickness of plywood, $k$ thermal conductivity, the subscript, $p w$ is ply wood and in is insulation and $\mathrm{s}$ is galvanized steel.

\section{RESULTS AND DISCUSSIONS}

In this research, the effect of the three design parameters on performance of the conventional solar 
still has been theoretically investigated. These design parameters are basin heat transfer coefficient, glass absorptivity and glass transmiss [5]. To perform the comparison, the model was solved under similar condition as the one used in the experimental study. Other parameters used in this model are shown in table 1. From the current theoretical model the hourly rate production, the accumulated rate production, and the saline water, basin and glass temperatures are calculated and compared with the experimental results (Fig. 2-Fig. 8 ). This is done iteratively to find the applicable values of basin heat transfer coefficient, glass absorptivity and glass transmissivity. The analysis showed that (see Fig. 2 ) the experimental and theoretical accumulated production rate are in very good agreement at $\mathrm{U}_{\mathrm{b}}=$ $5.9 \mathrm{~W} / \mathrm{m}^{2} \mathrm{~K}, \alpha_{\mathrm{g}}=0.075$ and $\tau_{\mathrm{g}}=0.845$ except around 11:00 a.m. where it shows a discrepancy of $30 \%$. Whereas the hourly production shows a good agreement with a maximum discrepancy of $23 \%$.. At the same conditions, the temperature deviation between theoretical and experiment is by $9.086 \%$ for saline water temperature $14.44 \%$ for basin temperature and $18.48 \%$ for the glass temperature. As an essential part of the current work, the effect of the three design parameters on the solar still performance is studied. During a design process, a theoretical model that predicts the solar still performance accurately plays a vital role. Thus, knowing the accurate values of these design parameters

in advance will result in a better solar still design. Figures 2-6 shows the effect of the basin heat transfer coefficient on the production and saline water, basin and glass temperatures. Ideally, a solar still must be perfectly insulated and so $U_{b}=0$, which produces the highest accumulated production. An actual solar will always have some basin heat loss depending on the insulation material and installation. Compared with ideal insulated solar still, a $U_{b}$ of $5.9,10,20$ and $30 \mathrm{~W} / \mathrm{m}^{2} \mathrm{~K}$, the accumulated production drops by $37.17 \%, 47.02 \%$, 58.53 and $64.02 \%$ respectively. The slope of the drop in production is steeper at low $U_{b}$ (Figure 9) at which the system must be designed. For example if the $\mathrm{U}_{\mathrm{b}}=$ $1 \mathrm{~W} / \mathrm{m}^{2} \mathrm{~K}$, the drop will $10.64 \%$ which is significantly large. Similarly, the effect of $\mathrm{U}_{\mathrm{b}}$ 's on the saline water, basin and glass temperatures is significantly large at low $\mathrm{U}_{\mathrm{b}}$ 's. The temperatures drops with increasing $\mathrm{U}_{\mathrm{b}}$ 's (see Figures 4-5). Based on average values, the deviation from the perfect insulated solar still for $\mathrm{U}_{\mathrm{b}}$ of $5.9,10,20$ and $30 \mathrm{~W} / \mathrm{m}^{2} \mathrm{~K}$ for the saline water is $14.51 \%, 18.015 \%$ and $24.94 \%$ respectively whereas for the basin the drop in temperature is $9.982 \%, 14.0 \%$
$19.32 \%$, and $22.18 \%$ and for the glass temperature is $25.77 \%, 28.88 \%, 32.75 \%$ and $34.71 \%$ respectively.

The effect of the glass absorptivity and transmissivity is also studied. The glass reflectance was taken as 0.08 for glass thickness up to $5 \mathrm{~mm}$ [22]. Therefore the trade off is then between the absorptivity and transmissivity so the sum of the three is always one. From Figures 7 and 8, the effect of these parameters is obvious. By reducing the glass absorptivity (i.e. increasing the glass transmissivity), the production rate increases due to the fact more solar radiation are passing to the basin. It is essential to use a glass with a low absorptivity in solar still to have high performance. At the same time, it is of great importance to incorporate in the theoretical model accurate values for these parameters in order to produce trustful results. This can be seen from the significant drop in the accumulated production for the absorptivity range of 0.01-0.1 (calculated based on the production at 0.01absorptivity). This drop in accumulated production for absorptivity of $0.025,0.05$, 0.075 , and 0.1 is $4.0 . \%, 10.63 \%, 17.04$ and $23.28 \%$ respectively.

The effect of the basin heat transfer coefficient, $U_{b}$ and glass absorptivity, $\alpha$ on the solar still efficiency are presented in Figures 10 and 11. As can be seen form Figure 10, the efficiency decreases linearly with increasing the glass cover absorptivity, $\alpha$. On the other hand, the drop in the solar still efficiency (Figure 11) is more profound when the heat transfer coefficient $U_{b}$ increases. Figure 11 shows that the efficiency decreases nonlinearly with increasing $U_{b}$, where it is steeper at low $U_{b}$. The average percentage of the heat loss through the basin is calculated relative the average radiation intensity. These averages are calculated over the 12 hours (6:00 -18:00) during which the system is operating. Figure 11 shows the nonlinear increase in the relative heat loss as expected. The effect of the basin heat transfer coefficient, $U_{b}$ and glass absorptivity, $\alpha$ are highly significant.

Table 1 applied parameters

\begin{tabular}{|l|c|c|c|c|}
\hline Parameter & Symbol & water & Basin & $\begin{array}{l}\text { Glass } \\
\text { cover }\end{array}$ \\
\hline Absorptivity & $\alpha$ & 0.05 & 0.90 & $0.01-0.1$ \\
\hline Transmissivity & $\tau$ & 0.90 & - & $0.91-0.82$ \\
\hline Emissivity & $\epsilon$ & 0.96 & - & 0.98 \\
\hline Reflectance & $r$ & 0.05 & 0.1 & 0.08 \\
\hline $\begin{array}{l}\text { Specific heat } \\
(\mathrm{J} / \mathrm{kg} \mathrm{K})\end{array}$ & $c_{p}$ & 4187 & 490 & 670 \\
\hline
\end{tabular}




\section{CONCLUSIONS}

Generally to develop a mathematical model it is required to know the basic design parameters such as the four basic properties that affect radiant energy transfer: transmittance, reflectance, absorptance, and emittance as well as all the external parameters such as the insulation characteristic, which dominate the overall heat transfer coefficient. Previous research using mathematical modeling either gave the values of these provided no clue of what values they used to obtain their results. This study is an attempt to predict production rate of the conventional solar still. In this research, the effect of the three design parameters $\left(U_{b}\right.$, $\alpha_{g}$ and $\tau_{g}$ ) on the performance of the solar still has been theoretically investigated and compared to the experimental results. Iteration was necessary to obtain the values of the design parameters that produce good matching with the experimental which $U_{b}=5 . \mathrm{W} /$ $m^{2} K, \alpha_{g}=0.075$ and $\tau_{g}=0.845$. The effect of $U_{b}$ found to be significantly large especially at low $U_{b}$. Compared to ideally perfectly insulated solar still, i.e. increasing $U_{b}$ up $30 \mathrm{~W} / \mathrm{m}^{2} \mathrm{~K}$, the accumulated production drops by $64.02 \%$ respectively. Similarly the effect of $U_{b}$ on the temperatures is significantly large at low $U_{b}$. Based on average values, the deviation from the perfect insulated solar still e.g. increasing $U_{b}$ up to $30 \mathrm{~W} / \mathrm{m}^{2} \mathrm{~K}$ for the saline water is $24.94 \%$ whereas for the basin the drop in temperature is $22.18 \%$ and for the glass temperature is $34.71 \%$ respectively. The effect of the $\alpha_{g}$ and $\tau_{g}$ is also studied. By reducing $\alpha_{g}$ (i.e. increasing $\tau_{g}$ ) the production rate increases due to the fact that more solar radiation are passing to the basin. It is essential to have a glass cover with low absorptivity in solar still to have high performance. The larger the absorptivity, the more significant the drop in the accumulated production. This drop for absorptivity of $0.025,0.05,0.075$, and 0.1 is $4.0 \%, 10.63 \%, 17.04$ and $23.28 \%$ respectively. Also the effect of the basin heat transfer coefficient, $U_{b}$ and glass absorptivity, $\alpha$ on the solar still efficiency was found to be highly significant. The relative heat loss is another measure to show influence of $U_{b}$ on the system production. In other words, the larger RHL, the less energy consumed by the saline water to evaporator.

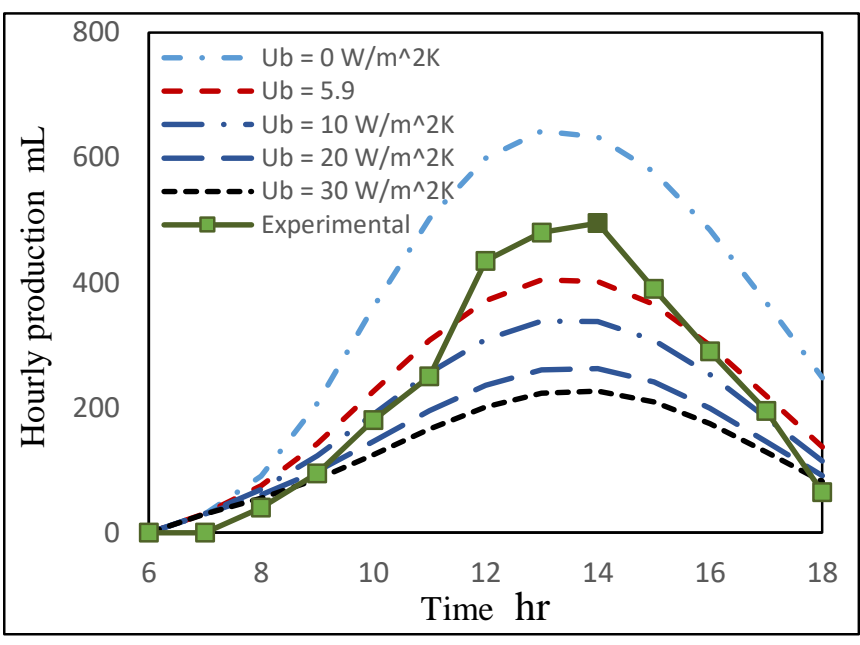

Figure 2 effect of basin overall heat transfer coefficient on accumulated production rate. $\alpha_{g}=$ $0.075, \tau_{g}=0.845$

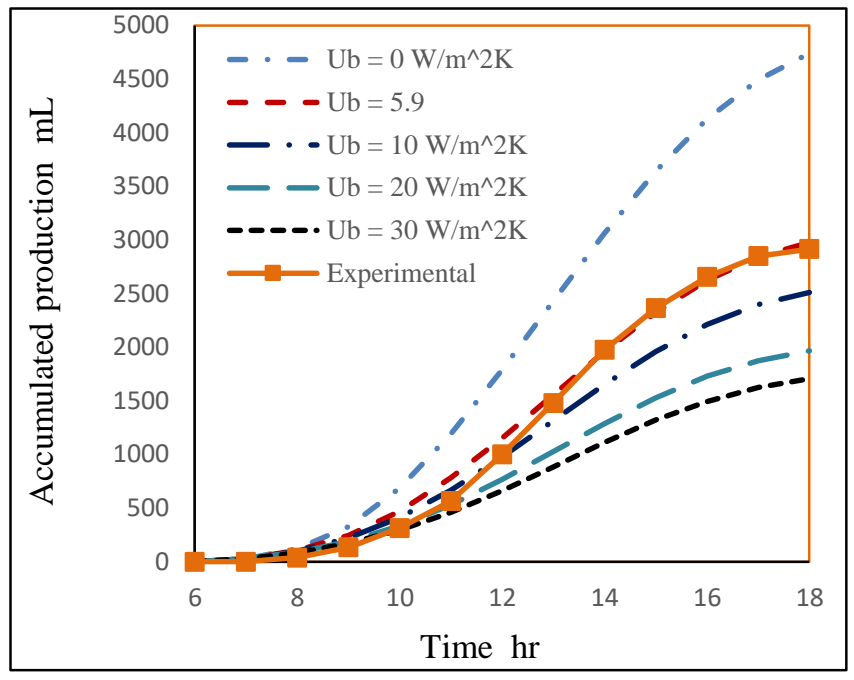

Figure 3 effect of basin overall heat transfer coefficient on hourly production rate. $\alpha_{g}=0.075$, $\tau_{g}=0.845$ 


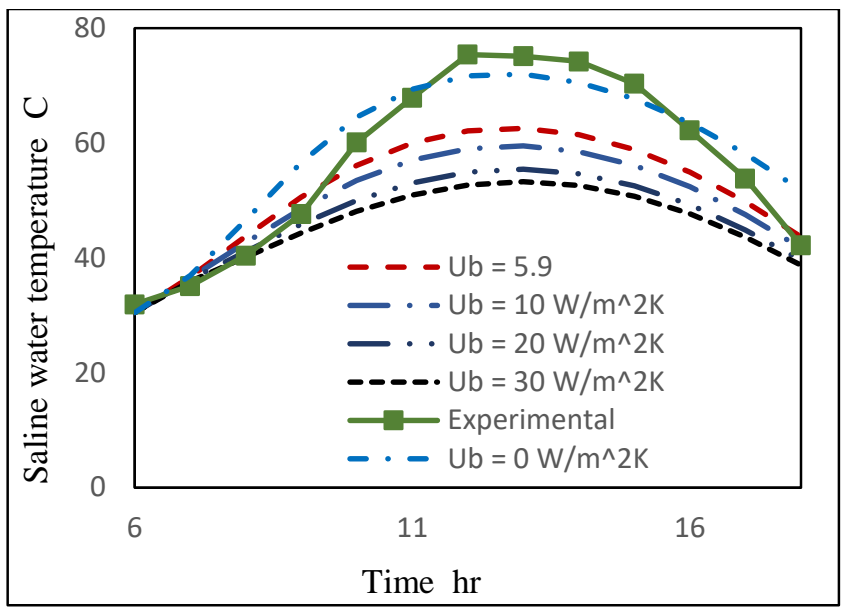

Figure 4 effect of basin overall heat transfer coefficient on saline water temperature. $\alpha_{g}=$

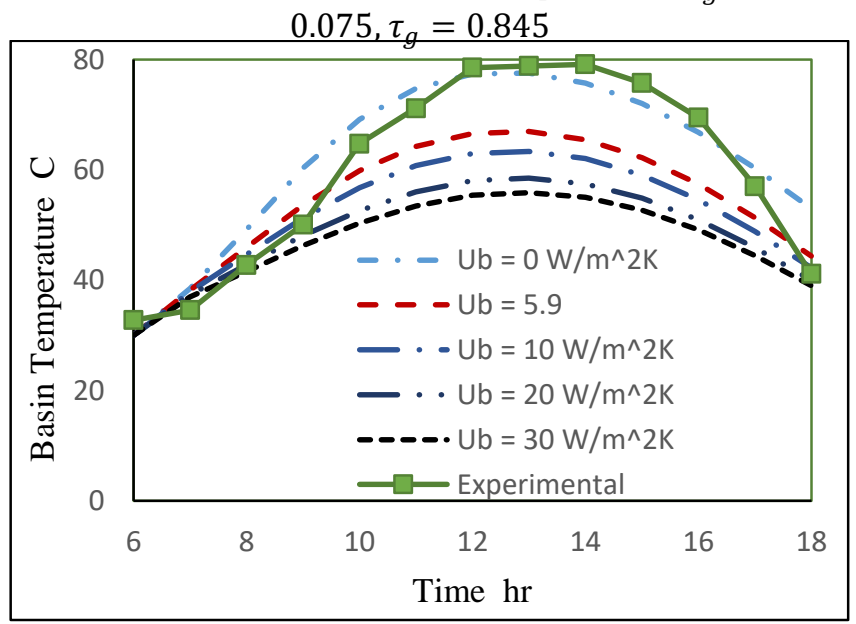

Figure 5 effect of basin overall heat transfer coefficient on basin temperature. $\boldsymbol{\alpha}_{\boldsymbol{g}}=0.075$,

$$
\tau_{g}=0.845
$$

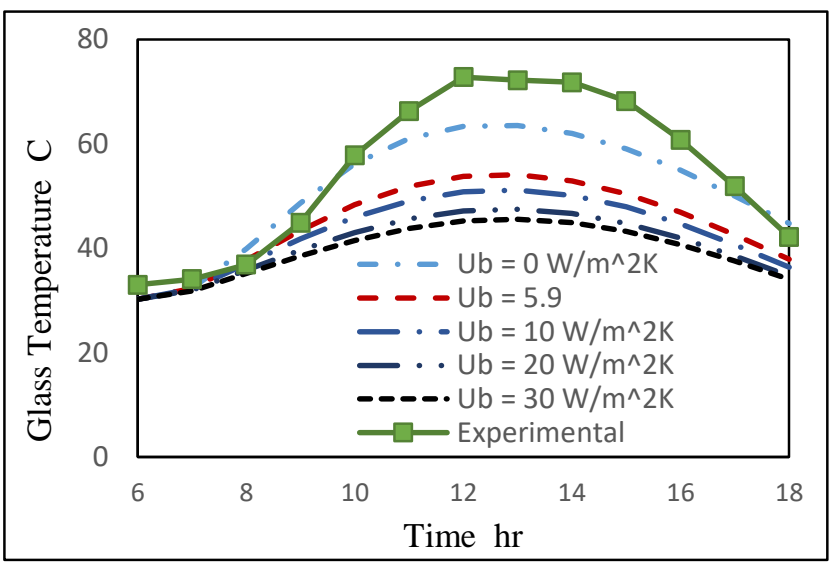

Figure 6 effect of basin overall heat transfer coefficient on glass temperature. $\alpha_{g}=0.075$,

$$
\tau_{g}=0.845
$$

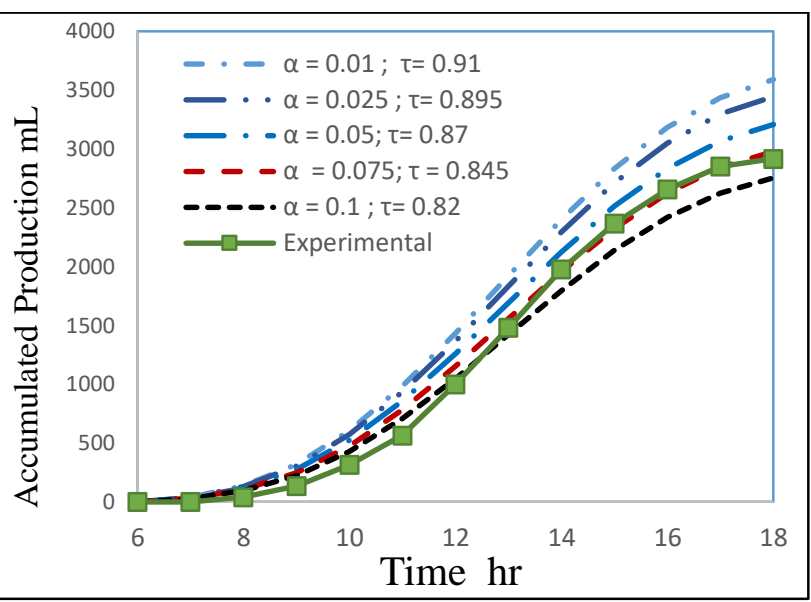

Figure 7 effect of Absorptivity and transmissivity on accumulated production rate. $U_{b}=5.9 \mathrm{~W} /$ $m^{2} K$, reflectivity $=0.08$

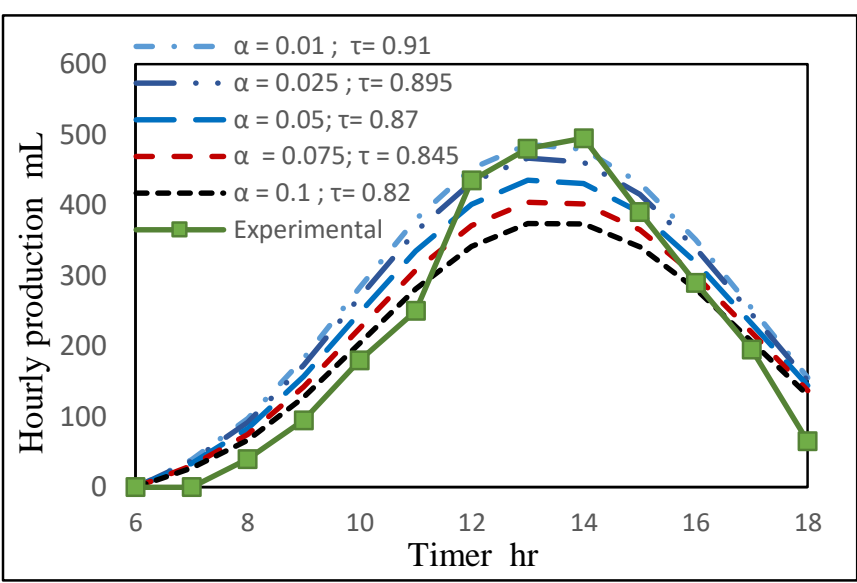

Figure 8 effect of Absorptivity and transmissivity on hourly production rate. $U_{b}=5.9 \mathrm{~W} / \mathrm{m}^{2} \mathrm{~K}$, reflectivity factor $=0.08$

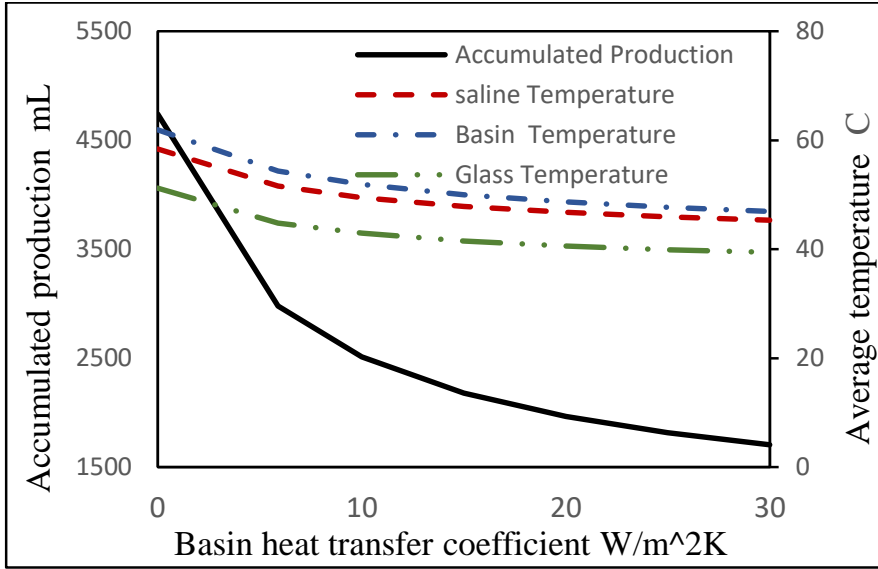

Figure 9 the accumulated production and temperatures versus the basin heat transfer coefficient $\alpha_{g}=0.075, \tau_{g}=0.845$, reflectivity factor 


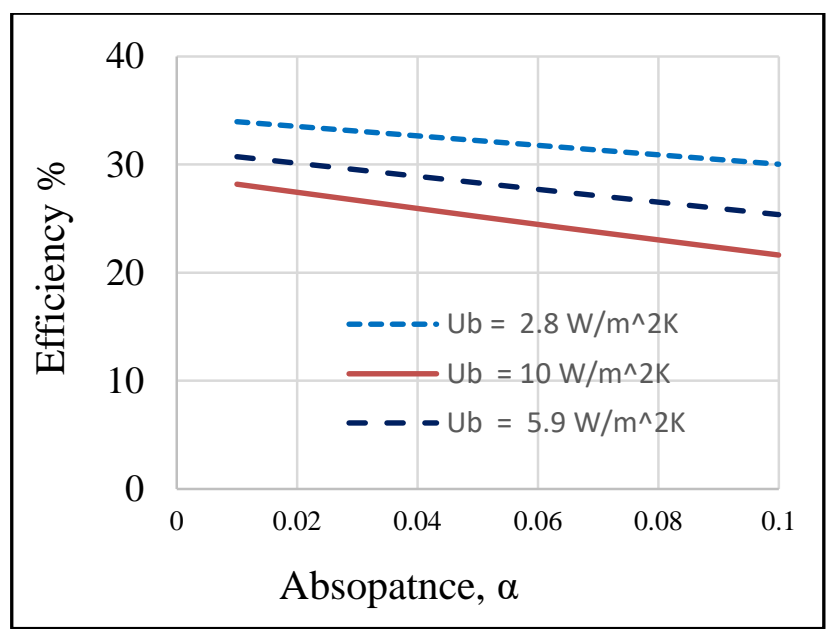

Figure 10 effect of Absorptivity and transmissivity on the efficiency, $U_{b}=5.9 \mathrm{~W} / \mathrm{m}^{2} \mathrm{~K}$, reflectivity factor =

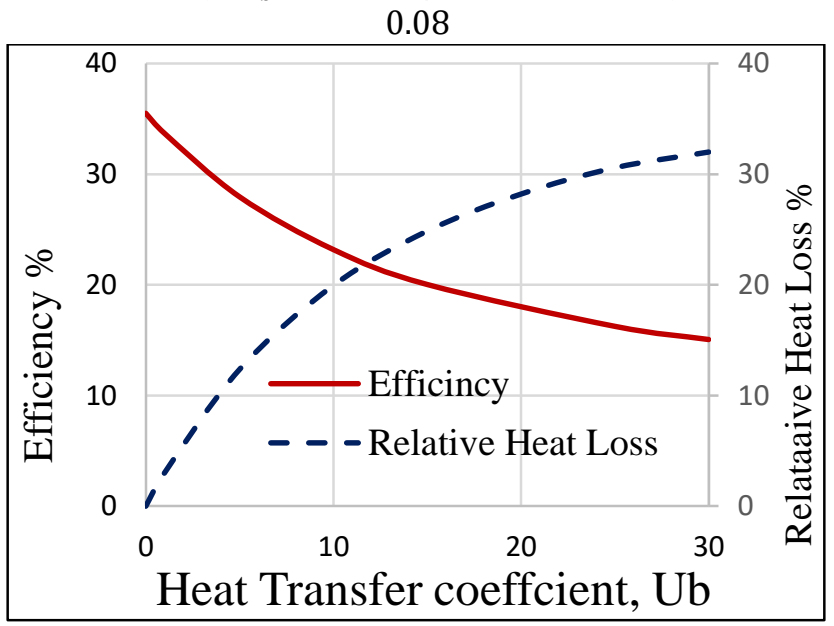

Figure 11 effect of the heat transfer coefficient on the efficiency and the relative heat loss. $\alpha_{g}=$ $0.075, \tau_{g}=0.845$, reflectivity factor $=0.08$

\section{NOMENCLATURES}

$\begin{array}{lll}A & \text { area } & {\left[\mathrm{m}^{2}\right]} \\ C & \text { specific heat } & {[\mathrm{J} / \mathrm{kg} \mathrm{K}]} \\ h & \text { heat transfer coefficient } & {\left[\mathrm{W} / \mathrm{m}^{2} \mathrm{~K}\right]} \\ h_{f g} & \text { enthalpy of evaporation at Tw } & {[\mathrm{J} / \mathrm{kg}]} \\ I_{t} & \text { intensity of solar radiation } & {\left[\mathrm{W} / \mathrm{m}^{2}\right]} \\ \bar{I}_{t} & \text { Daily average intensity of solar radiation }\left[\mathrm{W} / \mathrm{m}^{2}\right] \\ m & \text { mass, } & {[\mathrm{kg}]} \\ \mathrm{P} & \text { partial pressure } & {[\mathrm{Pa}]} \\ \mathrm{Q} & \text { rate of heat transfer } & {[\mathrm{W}]} \\ \bar{Q}_{b} & \text { daily average heat loss through basin }[\mathrm{W}]\end{array}$

RHL Relative Heat loss r reflectance

$T$ temperature,

$\mathrm{t}$ time

$U$ heat transfer coefficient,

$V$ wind velocity,

$\mathrm{x}$ thickness

$\left[{ }^{\circ} \mathrm{C}\right]$

[s]

$\left[W / m^{2} K\right]$

$[\mathrm{m} / \mathrm{s}]$

$[\mathrm{m}]$

\section{Greeks \\ $\alpha \quad$ absorptivity \\ $\varepsilon \quad$ emissivity \\ $\rho$ density, \\ $\tau$ transmissvity \\ $\eta \quad$ solar still efficiency

\begin{tabular}{ll}
\multicolumn{2}{l}{ Subscripts } \\
$a$ & ambient \\
$b$ & basin \\
$b w$ & basin-water \\
$c$ & convective \\
$e$ & evaporation \\
eq & equivalent \\
$f w$ & feed water \\
$g$ & glass \\
gsky & glass-sky \\
in & insulation \\
pw & plywood \\
$r$ & radiation \\
s & steel (galvanized) \\
$s w$ & side wall \\
$w$ & water \\
$w g$ & water-glass
\end{tabular}

\section{References}

[1] Ahmed H M, Ibrahim A G "Performance evaluation of a conventional solar still with different types and layouts of wick materials", J Energy Technologies and Policy, 6, pp 5-14, (2016).

[2] Alkaisi, A., Mossad, R., and Sharifian-Barforoush, A. "A Review of the Water Desalination Systems Integrated with Renewable Energy" Energy Procedia, Vol 110, pp 268-274, 2017.

[3] Ahmed, H.M., Alshutal, F.S., and Ibrahim, G "Impact of Different Configurations on Solar Still Productivity", Journal of Advanced Science and Engineering Research Vol. 3, No 2, 118-126, 2014

[4] Omara Z.M., Abdullahb, A. S., Kabeelc, A. K., Essaa F. A. "The cooling techniques of the solar stills' glass covers-A review" Renewable and Sustainable Energy Reviews 78. pp 176-193, 2017. 
[5] Ibrahim A G, and Ahmed H M, "A theoretical Analysis of a Conventional Solar Still with Different Types of Wick Materials" Unpublished research

[6] Sarray, Y., Hidouri, N., Mchirgui, A., A. B., Brahim "Study of heat and mass transfer phenomena and entropy rate of humid air inside a passive solar still". Desalination 409, pp 80-95, 2017.

[7] A.F. Muftah,M.A. Alghoul, A. Fudholi,M.M. Abdulmajeed, K. Sopian, Factors affecting basin type solar still productivity: a detailed review, Renew. Sust. Energ. Rev. 32, pp 430-447, 2014.

[8] K.R. Ranjan, S.C. Kaushik, N.L. Panwar, Energy and exergy analysis of passive solar distillation systems, Int. J. Low Carbon Technol. 1-11, 2013.

[9] Abd Elkader M, Safwat Nafy A, Abd Elmotalip A, Mabrouk A. A, "Experimental Evaluation of Solar Still Mathematical Models", Fourth International Water Technology Conference IWTC 99, Alexandria, Egypt, 2008.

[10] El-Agouz S.A., El-Samadony, Y.A.F., and Kabeelm A.E. "Performance evaluation of a continuous flow inclined solar still desalination system", Energy Conversion and Management 101, pp 606-615, 2015.

[11] G. P. Mitalas G P, and Stephenso G D, 1962, "Absorption and Transmission of Thermal Radiation by Single and Double Glazed Windows", National research Council Canada, the Division of Building Research, Research Paper No. 173

[12] Bakari R, Minja R J A,1 and.Njau K N, "Effect of Glass Thickness on Performance of Flat Plate Solar Collectors for Fruits Drying" Journal of Energy, V 2014, Article ID 247287.

[13] Kumar P. V., Kumar A., Prakash O., Kaviti A. K., "Solar stills system design: A review", Renewable and Sustainable Energy Reviews 51, pp 153-181, 2015.

[14] Ahmed H.M., Hamza R. M, Ibrahim G., and Mahmood Z., " Temperature Analysis of Conventional Solar Still linked to Passive Cylindrical Condensers" Journal of Advanced Science and Engineering Research Vol. 3, No 3, pp 243-251, 2013.

[15] Kumar A., Esakkimuthu, G., Murugave K. K.," Performance enhancement of a single basin single slope solar still using agitation effect and external condenser" Desalination 399, pp 198-202, 2016.

[16] Alaudeen A, Johnson K, Ganasundar P, Abuthahir A S, Srithar K, "Study on stepped type basin in solar still", J KSU Engineering sciences, 26, 176-183, 2014.

[17] Ahmed H M, Ibrahim A G, "Performance evaluation of a conventional solar still with different types and layouts of wick materials", J Energy Technologies and Policy, 6, pp 5-14, 2016

[18] The following Salem Algarni Darin Nutter, PhD, PE, Survey of Sky Effective Temperature Models Applicable to Building Envelope Radiant Heat Transfer, AT-15-029, Conference. Proceeding by ASHRAE, 2015

[19] Haruna, I U, Yerima M, Pukuma A D, Sambo II, "Experimental investigation of the performance of basin type single-slope solar still", I J Science and technology, 3, pp 169-174, 2014.

[20] Jamil B, Akhtar N,(2014) "Desalination of Brackish Water using Solar Stills-A Review", Proceedings of the International Conference on Environment and Energy (ICEE-2014), 201

[21] Madhlopa A, Clarke J A, " Computation of irradiance in a solar still by using a refined algorithm", Renewbale energy, 51, pp 13-21, 2013.

[22] Gurdian SunGuard Advanced Architectural Glass. http://www.me.en.sunguardglass.com/cs/groups/ sunguardme/documents/native/gi_005564.pdf Or www.SunGuardGlass.com 